\title{
PENGARUH APLIKASI ABU TERBANG BATUBARA DAN PUPUK KANDANG SEBAGAI BAHAN AMELIORAN TERHADAP PERTUMBUHAN TANAMAN KANGKUNG (Ipomea reptans Poir.)
}

\section{THE EFFECT OF COAL FLY ASH AND MANURE APPLICATIONS AS AN AMELIORANT MATERIAL FOR THE GROWTH OF WATER SPINACH PLANT (Ipomea reptans Poir.)}

\author{
Safitri Febriana ${ }^{1)}$, Priyadi $^{1 *}$, Rianida Taisa $^{2)}$ \\ ${ }^{1}$ Sekolah Tinggi Ilmu Pertanian Dharma Wacana \\ Jalan Kenanga No 03 Mulyojati 16 Kota Metro 34125, Lampung Indonesia \\ ${ }^{2)}$ Politeknik Negeri Lampung \\ Jalan Soekarno-Hatta No. 10, Rajabasa, Bandar Lampung, Lampung, Indonesia \\ Email:priyadigege@ymail.com
}

\begin{abstract}
Fly ash is a waste from coal combustion that has the potential as soil ameliorant. This study aims to determine the effect of coal fly ash and manure application on the growth of water spinach plants. The study was conducted using a Randomized Complete Block Design (RCBD), which was arranged in factorial with three replications. The first factor was the dose of fly ash consisting of four levels $\left(0\right.$ ton ha ${ }^{-1}, 50$ ton $\mathrm{ha}^{-1}, 100$ ton $\mathrm{ha}^{-1}$, and 150 ton ha $\mathrm{a}^{-1)}$ and second factor was the dose of manure with three levels (10 ton $h a^{-1}, 20$ ton ha ${ }^{-1}$, and 30 ton ha $\left.{ }^{-1}\right)$. The homogenity of the research data was tested by Bartlett test and Tuckey tested the data in addictiveness then analyzed with variance and continued with the Least Significant Difference test (LSD) at $5 \%$ level. The results showed that (1) an increase in the application dose of coal fly ash affected to decrease in plant height, the number of leaves, dry weight of water spinach, root length, the number of roots, and dry weight of roots, (2) the application of manure is not increased the growth of water spinach, (3) no interaction between fly ash and manure on the growth of water spinach.
\end{abstract}

Keywords: Acid soil, ameliorant, fly ash, manure, water spinach.

\begin{abstract}
ABSTRAK
Fly ash merupakan limbah hasil pembakaran batubara yang berpotensi sebagai bahan ameliorant. Tujuan dari penelitian ini yaitu untuk mengetahui pengaruh palikasi abu terbang batubara dan pupuk kendang terhadap pertumbuhan tanaman kangkung. Penelitian ini menggunakan Rancangan Acak Kelompok Lengkap (RAKL) yang disusun secara faktorial. Faktor pertama adalah dosis abu terbang terdiri atas 4 level $\left(0\right.$ ton ha' ${ }^{-1}, 50$ ton ha ${ }^{1}, 100$ ton ha ${ }^{-1}$, and 150 ton ha $\left.{ }^{-1}\right)$ dan faktor kedua adalah dosis pupuk kandang dengan 3 level $\left(10\right.$ ton ha ${ }^{-1}, 20$ ton ha $\mathrm{a}^{-1}$, and 30 ton ha $\left.{ }^{-1}\right)$. Homogenitas data diuji dengan menggunakan uji Bartlett dan ketidakaditifan data dengan uji Tukey kemudian dianalisis dengan sidik ragam dan dilanjutkan dengan uji Beda Nyata Terkecil (BNT) pada taraf 5\%. Hasil penelitian menunjukkan bahwa (1) peningkatan dosis aplikasi abu terbang batubara menyebabkan penurunan terhadap tinggi tanaman, jumlah daun, bobot kering berangkasan, panjang akar, jumlah akar, dan bobot kering berangkasan tanaman kangkung, (2) aplikasi pupuk kandang tidak meningkatkan pertumbuhan tanaman kangkung, (3) tidak terdapat interaksi antara abu terbang batubara dan pupuk kandang terhadap pertumbuhan tanaman kangkung.
\end{abstract}

Kata kunci: Abu terbang batubara, amelioran, kangkung, pupuk kandang, tanah asam. 


\section{PENDAHULUAN}

Batubara merupakan salah satu bahan bakar yang jumlahnya cukup melimpah di Indonesia yaitu kurang lebih 149 miliar ton sumber daya batubara dan 37,6 miliar ton cadangan batubara. Jumlah tersebut tersebar di Sumatera (32\%), Kalimantan (67\%) dan sisanya (1\%) tersebar di Pulau Jawa, Sulawesi dan Irian Jaya (PSDMBP, 2019). Pembakaran batubara menghasilkan sekitar 5\% polutan padat berupa abu ( $f l y$ ash dan bottom ash), dimana sekitar 10-20\% adalah abu dasar (bottom ash) dan sekitar 80-90\% abu terbang (fly ash) dari total abu yang dihasilkan (Wardani, 2008)). Fly ash memiliki potensi yang besar di bidang pertanian karena dapat dijadikan sebagai bahan amelioran dan mereklamasi lahan bekas tambang (Ram \& Masto, 2010); (Skousen, Ziemkiewicz, \& Yang, 2012); (Ram \& Masto, 2014).

Menurut (Kishor, A.K, \& Kumar, 2010), secara kimia abu terbang batubara merupakan mineral aluminosilikat yang banyak mengandung unsur hara seperti Magnesium (Mg) 3,94\%, Ca (7,90\%), Natrium (Na) 3,14 \%, Silika (Si) 24,4 \%, Besi (Fe) 8,60\%,Alumunium (Al) 23,02\%, Sulfur (S) 3,82\%, Fosfor (P) 0,24 \%, dan Kalium (K) 1,52\%, yang umumnya bersifat alkalis ( $\mathrm{pH} 8-12)$. Sedangkan secara fisik memiliki ukuran partikel debu dan memiliki karakteristik kapasitas pengikat air dari sedang sampai tinggi. Disisi lain abu terbang batubara mengandung unsur-unsur logam berat, dan menurut Peraturan Pemerintah No. 85 tahun 1999 mengklasifikasikan abu terbang batubara sebagai limbah bahan berbahaya dan beracun(B3) karena memiliki kandungan logam berat seperti $\mathrm{Pb}$ (timbal), Kadmium (Cd), Tembaga (Cu),
Arsen (As) dan lain-lain. Logam berat pada abu terbang batubara diantaranya bersifat mobil sehingga mudah diserap oleh tanaman dan bersifat toksik. Sehingga penggunaan abu terbang batubara dibidang pertanian masih terbatas dan harus menyesuaikan dengan ketentuan peraturan yang berlaku.

Terlepas dari hal tersebut, menurut (Sondari \& Nurkhalidah, 2012); (Jarosz-Krzemiñska \& Poluszyñska, 2020), abu terbang dapat berfungsi sebagai bahan amelioran yang mampu memperbaiki tanah dengan meningkatkan $\mathrm{pH}$ pada tanah masam. Selain itu, dengan pemanfaatan abu terbang batubara dapat mengatasi masalah kemasaman tanah dan menurunkan tingkat pencemaran lingkungan akibat hasil pembakaran batubara yang semakin melimpah jumlahnya. Penggunaan bahan amelioran berupa abu terbang batubara dinilai dapat memperbaiki kesuburan tanah.

Kemasaman tanah dapat diperbaiki dengan pengapuran, tetapi tanah masam memerlukan pengapuran dalam jumlah yang besar dan diberikan secara terus-menerus, sehingga memerlukan biaya yang mahal. Penggunaan abu terbang batubara sebagai pengganti kapur dinilai lebih efisien karena memanfaatkan limbah yang tidak digunakan. Abu terbang batubara mampu menetralkan tanah dengan kemasaman tinggi dan sulit ditanami, dapat memperbaiki struktur tanah menjadi gembur dan meningkatkan kemampuan tanah menyimpan air.

Selain abu terbang batubara, pupuk kandang sapi juga merupakan bahan amelioran organik yang mampu memperbaiki sifat fisika, kimia, dan biologi tanah (Sari, Sudradjat, \& Sugiyanta, 2015) seperti meningatkan porositas, $\mathrm{pH}$, kapasitas air, kapasitas 
tukar kation (KTK), serta meningkatkan pertumbuhan mikro-organisme dalam tanah(Leszczynska \& Malina, 2011). Sekitar 20 - $70 \%$ KTK tanah umumnya bersumber pada koloid, sehingga terdapat korelasi antara bahan organik dengan KTK tanah.

Pupuk kandang sapi memiliki kandungan unsur hara makro (N, P, K, Ca, Mg dan S) dan unsur hara mikro (Zn, Cu, Mo, Co, B, Mn dan Fe) yang dapat memperbaiki tanah masam dan mampu meningkatkan pertumbuhan tanaman. Pupuk kandang sapi dapat meningkatkan biomassa dan mengurangi pencucian pada tanah berpasir(Priyadi, Mangiring, \& Jamaludin, 2018) serta cocok sebagai bahan amelioran (Epelde et al., 2018). Pemberian bahan organik dapat meningkatkan efektivitas dan efesiensi pupuk anorganik (NPK) terhadap pertumbuhan tanaman (Widowati, 2012). Selain itu, bahan organik dapat mengkhelat logam sehingga mampu menurunkan serapan logam berat oleh tanaman (Brown, Chaney, \& Hallfrisch, 2004). Menurut Tan (1991), menyatakan bahwa dengan memberikan humus pada tanah masam akan menyebabkan fraksi-fraksi logam berat mengalami pengkhelatan logam oleh bahan organik, sehingga ketersediaan logam akan menurun.

Diantara berbagai jenis tanaman, kangkung tergolong tanaman yang mempunyai kemampuan mengakumulasi logam berat, sehingga sering digunakan sebagai tanaman fitoremidiator. Tanaman kangkung mampu mengakumulasi kandungan beberapa logam berat antara lain 10 ppm Hg, 100 ppm Cd, 1000 ppm $\mathrm{Co}, \mathrm{Cr}, \mathrm{Cu}$, dan $\mathrm{Pb}, 10.000$ ppm unsur Ni dan $\mathrm{Zn}$ (Aiyen, 2004). Berdasarkan uraian di atas maka perlu dilakukan penelitian tentang pengaruh aplikasi abu terbang batubara dan pupuk kandang sebagai bahan amelioran terhadap pertumbuhan tanaman kangkung.

Penelitian ini bertujuan (1) untuk mempelajari pengaruh aplikasi abu terbang batubara terhadap pertumbuhan tanaman kangkung, (2) untuk mempelajari pengaruh aplikasi pupuk kandang terhadap pertumbuhan tanaman kangkung, (3) untuk mengetahui interaksi antara abu terbang batubara dan pupuk kandang terhadap pertumbuhan tanaman kangkung.

\section{BAHAN DAN METODE}

Penelitian dilaksanakan di Kebun percobaan STIPER Dharma Wacana Metro dari Desember 2019 sampai Maret 2020. Rancangan yang digunakan adalah Rancangan Acak Kelompok Lengkap (RAKL) yang disusun secara faktorial. Faktor pertama adalah dosis abu terbang batubara $(\mathrm{F})$ terdiri atas 4 level yaitu; $\mathrm{fl}=0 \mathrm{t}$ $\mathrm{ha}^{-1}, \mathrm{f} 2=50 \mathrm{tha}^{-1}, \mathrm{f} 3=100 \mathrm{tha}^{-1}, \mathrm{f} 4=150 \mathrm{tha}^{-1}$. Faktor kedua adalah dosis pupuk kandang $(\mathrm{M})$ terdiri dari 3 level yaitu; $\mathrm{m} 1=10 \mathrm{tha}^{-1}, \mathrm{~m} 2=20 \mathrm{tha}^{-1}, \mathrm{~m} 3=30 \mathrm{tha}^{-1} .12$ kombinasi perlakuan tersebut diulang sebanyak 3 kali.

Persiapan media tanam dilakukan dengan mencampur tanah jenis podsolik merah kuning seberat $3 \mathrm{~kg}$ (yang sudah diayak) dengan abu terbang batubara dan pupuk kandang sapi sesuai dosis masing-masing perlakuan. Selanjutnya dilakukan penanaman benih kangkung ke dalam masing-masing pot percobaan sebanyak 3 buah. Kegiatan pengamatan dilakukan mulai dari 10 hst sampai dengan dengan 25 hst dengan rentan waktu pengamatan adalah 5 hari.

Parameter yang diamatimeliputi tinggi tanaman (cm), jumlah daun (helai), bobot kering berangkasan (g), jumlah akar (buah), panjang akar (cm), dan bobot 
kering akar (g). Data hasil pengamatan diuji homogenitasnya dengan uji Bartlett dan ketidakaditifan data dengan uji Tukey kemudian dianalisis dengan sidik ragam dan dilanjutkan dengan uji Beda Nyata Terkecil (BNT) pada taraf 5\%.

\section{HASIL DAN PEMBAHASAN}

Pengaruh Aplikasi Abu Terbang Batubara dan Pupuk Kandang terhadap Tinggi Tanaman Kangkung

Hasil penelitian menunjukkan bahwa peningkatan dosis abu terbang batubara mempengaruhi terhadap penurunan tinggi tanaman kangkung. Ringkasan analisis sidik ragam pengaruh aplikasi abu terbang batubara dan pupuk kandang terhadap tinggi tanaman kangkung disajikan pada Tabel 1. Data ini menunjukkan bahwa aplikasi pupuk kandang tidak nyata terhadap tinggi tanaman kangkung. Interaksi antara abu terbang batubara dan pupuk kandang juga

Tabel 1. Ringkasan analisis sidik ragam tinggi tanaman kangkung akibat aplikasi abu terbang batubara dan pupuk kandang

\begin{tabular}{lc}
\hline \multicolumn{1}{c}{ Sumber Keragaman } & Tinggi tanaman $(\mathrm{cm})$ \\
\hline Abu terbang batubara (A) & $4,06^{*}$ \\
Pupuk kandang (K) & $2,98^{\text {th }}$ \\
Interaksi AxK & $1,32^{\text {th }}$ \\
\hline
\end{tabular}

Ket: ${ }^{*}=$ berpengaruh nyata pada taraf $5 \%$, $\mathrm{tn}=$ tidak berpengaruh nyata

Tabel 2. Tinggi tanaman akibat aplikasi abu terbang batubara

\begin{tabular}{lc}
\hline Dosis abu terbang batubara & Tinggi tanaman $(\mathrm{cm})$ \\
\hline $\mathrm{A}_{0}\left(0 \mathrm{t} \mathrm{ha}^{-1}\right)$ & $27,24 \mathrm{~A}$ \\
$\mathrm{~A}_{1}\left(50 \mathrm{tha}^{-1}\right)$ & $26,78 \mathrm{AB}$ \\
$\mathrm{A}_{2}\left(100 \mathrm{t} \mathrm{ha}^{-1}\right)$ & $24,64 \mathrm{BC}$ \\
$\mathrm{A}_{3}\left(150 \mathrm{t} \mathrm{ha}^{-1}\right)$ & $24,02 \mathrm{C}$ \\
\hline BNT $5 \%$ & 2,30 \\
\hline
\end{tabular}

Ket: Angka yang diikuti huruf yang sama pada kolom yang sama tidak berbeda nyata dengan uji BNT pada taraf 5\%. tidak nyata terhadap tinggi tanaman. Pengaruh abu terbang batubara terhadap tinggi tanaman kangkung disajikan pada Tabel 2. Tabel 2 menunjukkan bahwa peningkatan dosis abu terbang batubara memberikan pengaruh dalam meningkatkan tinggi tanaman kangkung, semakin tinggi dosis abu terbang batubara menyebabkan penurunan terhadap tinggi tanaman, namun tidak berbeda secara signifikan. Pemberian abu terbang batubara dengan dosis $0 \mathrm{t} \mathrm{ha}^{-1}$ menunjukkan tananam tertinggi, sedangkan pemberian abu terbang batubara dengan dosis 150 tha $^{-1}$ memberikan pengaruh yang paling rendah terhadap tinggi tanaman kangkung. Hal ini menunjukkan bahwa pemberian abu terbang batubara hanya dapat diberikan pada jumlah dosis yang rendah. Hasil analisis menunjukkan dengan semakin meningkatnya pemberian dosis abu terbang maka tinggi tanaman mengalami penurunan tetapi tidak signifikan. Hal ini diduga, kandungan logam berat pada abu terbang batubara tersebut menjadi penghambat pertumbuhan tanaman pada tanaman kangkung.

\section{Pengaruh Aplikasi Abu Terbang Batubara dan} Pupuk Kandang terhadap Jumlah Daun Tanaman Kangkung

Hasil penelitian menunjukkan bahwa peningkatan dosis abu terbang batubara mempengaruhi terhadap penurunan jumlah daun tanaman kangkung. Ringkasan analisis sidik ragam pengaruh aplikasi abu terbang batubara dan pupuk kandang terhadap jumlah daun tanaman kangkung disajikan pada Tabel 3. Hasil menunjukkan bahwa aplikasi pupuk kandang tidak nyata terhadap jumlah daun tanaman kangkung. Interaksi antara abu terbang batubara dan pupuk kandang juga 
tidak nyata terhadap jumlah daun tanaman. Pengaruh abu terbang batubara terhadap jumlah daun tanaman kangkung disajikan pada Tabel 4. Tabel 4 menunjukkan bahwa pemberian abu terbang batubara dengan dosis 0 $\mathrm{t} \mathrm{ha}^{-1}$ menunjukan jumlah daun tanaman tanaman kangkung tertinggi. Hal ini menunjukkan bahwa pemberian abu terbang batubara mempengaruhi pada penurunan jumlah daun tanaman kangkung. Tanaman kangkung sudah cukup memperoleh unsur hara dari media tanam yang digunakan, sehingga dengan penambahan abu terbang batubara tidak memengaruhi jumlah daun tanaman.

\section{Pengaruh AplikasiAbu Terbang Batubara dan Pupuk} Kandang terhadap Bobot Kering Berangkasan

\section{Tanaman Kangkung}

Hasil penelitian menunjukkan bahwa peningkatan dosis abu terbang batubara nyata

Tabel 3. Ringkasan analisis sidik ragam jumlah daun tanaman kangkung akibat aplikasi abu terbang batubara dan pupuk kandang

\begin{tabular}{lc}
\hline \multicolumn{1}{c}{ Sumber Keragaman } & Jumlah Daun (helai) \\
\hline Abu terbang batubara (A) & $4,25^{*}$ \\
Pupuk kandang (K) & $1,31^{\text {tn }}$ \\
Interaksi AxK & $0,26^{\text {tn }}$ \\
\hline
\end{tabular}

Ket: ${ }^{*}=$ berpengaruh nyata pada taraf $5 \%$,

tn $=$ tidak berpengaruh nyata

Tabel 4. Jumlah daun tanaman akibat aplikasi abu terbang batubara

\begin{tabular}{lc}
\hline Dosis abu terbang batubara & Jumlah Daun (helai) \\
\hline $\mathrm{A}_{0}\left(0 \mathrm{t} \mathrm{ha}^{-1}\right)$ & $12,20 \mathrm{~A}$ \\
$\mathrm{~A}_{1}\left(50 \mathrm{tha}^{-1}\right)$ & $11,31 \mathrm{~B}$ \\
$\mathrm{~A}_{2}\left(100 \mathrm{tha}^{-1}\right)$ & $11,16 \mathrm{~B}$ \\
$\mathrm{~A}_{3}\left(150 \mathrm{tha}^{-1}\right)$ & $10,84 \mathrm{~B}$ \\
\hline BNT $5 \%$ & 0,83 \\
\hline
\end{tabular}

Ket: Angka yang diikuti huruf yang sama pada kolom yang sama tidak berbeda nyata dengan uji BNT pada taraf 5\%. terhadap bobot kering berangkasan tanaman kangkung. Ringkasan analisis sidik ragam pengaruh aplikasi abu terbang batubara dan pupuk kandang terhadap bobot kering berangkasan tanaman kangkung disajikan pada Tabel 5. Hasil menunjukkan bahwa aplikasi pupuk kandang tidak berpengaruh nyata terhadap bobot kering berangkasan tanaman kangkung, dan tidak terdapat interaksi antara abu terbang batubara dan pupuk kandang terhadap bobot kering berangkasan tanaman. Pengaruh abu terbang batubara terhadap bobot kering berangkasan tanaman kangkung disajikan pada Tabel

6. Data menunjukkan bahwa pemberian abu terbang batubara dengan dosi s $0 \mathrm{t} \mathrm{ha}^{-1}$ menunjukkan bobot kering berangkasan tanaman tertinggi, tetapi tidak berbeda terhadap semua perlakuan dosis abu terbang

Tabel 5. Ringkasan analisis sidik ragam bobot kering berangkasan tanaman kangkung akibat aplikasi abu terbang batubara dan pupuk kandang

\begin{tabular}{lc}
\hline \multicolumn{1}{c}{ Sumber Keragaman } & $\begin{array}{c}\text { Bobot Kering } \\
\text { Berangkasan }(\mathrm{g})\end{array}$ \\
\hline Abu terbang batubara $(\mathrm{A})$ & $6,77^{*}$ \\
Pupuk kandang $(\mathrm{K})$ & $0,38^{\text {tn }}$ \\
Interaksi AxK & $0,40^{\text {tn }}$ \\
\hline Ket: Angka yang diikuti huruf yang sama pada kolom yang \\
\multicolumn{2}{c}{ sama tidak berbeda nyata dengan uji BNT pada taraf $5 \%}$.
\end{tabular}

Tabel 6. Bobot kering berangkasan tanaman akibat aplikasi abu terbang batubara

\begin{tabular}{lc}
\hline $\begin{array}{c}\text { Dosis abu terbang } \\
\text { batubara }\end{array}$ & Bobot Kering Berangkasan \\
$(\mathrm{g})$
\end{tabular}


batubara. Hal ini menunjukkan bahwa penambahan dosis abu terbang batubara hanya dapat diberikan dalam dosis rendah. Berdasarkan hasil penelitian menunjukkan bahwa semakin tinggi dosis aplikasi abu terbang batubara, maka bobot kering tanaman juga akan semakin rendah.

\section{Pengaruh Aplikasi Abu Terbang Batubara dan Pupuk Kandang terhadap PanjangAkar Tanaman}

\section{Kangkung}

Hasil penelitian menunjukkan bahwa aplikasi abu terbang batubara nyata terhadap panjang akar tanaman kangkung. Ringkasan analisis sidik ragam pengaruh aplikasi abu terbang batubara dan pupuk kandang terhadap panjang akar tanaman kangkung disajikan pada Tabel 7. Data menunjukkan bahwa aplikasi pupuk kandang tidak berpengaruh nyata terhadap panjang akar tanaman kangkung, dan tidak terdapat interaksi antara abu terbang batubara dan pupuk kandang terhadap panjang akar tanaman. Pengaruh abu terbang batubara terhadap panjang akar tanaman kangkung disajikan pada Tabel 8. Tabel 8 menunjukkan bahwa peningkatan dosis abu terbang batubara memberikan pengaruh terhadap penurunan panjang akar tanaman, tetapi tidak berbeda dengan semua dosis perlakuan. Hal ini menunjukkan bahwa pemberian abu terbang batubara tidak memengaruhi panjang akar tanaman kangkung. Panjang akar tanaman kangkung mengalami penurunan seiring dengan penambahan jumlah dosis abu terbang batubara. Hal ini diduga kandungan logam berat pada fly ash batubara menghambat pertumbuhan akar, sehingga akar tanaman tidak mampu menyerap unsur hara dan tumbuh dengan
Tabel 7. Ringkasan analisis sidik ragam panjang akar tanaman kangkung akibat aplikasi abu terbang batubara dan pupuk kandang

\begin{tabular}{lc}
\hline \multicolumn{1}{c}{ Sumber Keragaman } & Panjang Akar $(\mathrm{cm})$ \\
\hline Abu terbang batubara $(\mathrm{A})$ & $10,16^{*}$ \\
Pupuk kandang $(\mathrm{K})$ & $2,3^{\text {tn }}$ \\
Interaksi AxK & $0,49^{\text {tn }}$ \\
\hline
\end{tabular}

Ket: ${ }^{*}=$ berpengaruh nyata pada taraf $5 \%$, $\mathrm{tn}=$ tidak berpengaruh nyata

Tabel 8. Panjang akar tanaman akibat aplikasi abu terbang batubara

\begin{tabular}{lc}
\hline $\begin{array}{c}\text { Dosis abu terbang } \\
\text { batubara }\end{array}$ & Panjang Akar $(\mathrm{cm})$ \\
\hline $\mathrm{A}_{0}\left(0 \mathrm{tha}^{-1}\right)$ & $27,24 \mathrm{~A}$ \\
$\mathrm{~A}_{1}\left(50 \mathrm{t} \mathrm{ha}^{-1}\right)$ & $26,78 \mathrm{AB}$ \\
$\mathrm{A}_{2}\left(100 \mathrm{tha}^{-1}\right)$ & $24,64 \mathrm{BC}$ \\
$\mathrm{A}_{3}\left(150 \mathrm{tha}^{-1}\right)$ & $24,02 \mathrm{C}$ \\
\hline BNT $5 \%$ & 2,30 \\
\hline
\end{tabular}

Ket: Angka yang diikuti huruf yang sama pada kolom yang sama tidak berbeda nyata dengan uji BNT pada taraf 5\%.

Tabel 9. Ringkasan analisis sidik ragam jumlah akar tanaman kangkung akibat aplikasi abu terbang batubara dan pupuk kandang

\begin{tabular}{lc}
\hline \multicolumn{1}{c}{ Sumber Keragaman } & Jumlah akar \\
\hline Abu terbang batubara (A) & $7,58^{*}$ \\
Pupuk kandang (K) & $1,41^{\text {tn }}$ \\
Interaksi AxK & $1,37^{\text {tn }}$ \\
\hline
\end{tabular}

Ket: ${ }^{*}=$ berpengaruh nyata pada taraf $5 \%$, tn $=$ tidak berpengaruh nyata

baik. Hasil penelitian (Ahmad, Jamil, \& Zahir, 2012; Yourtchi \& Bayat, 2013) menjelaskan bahwa kandungan logam berat $\mathrm{Cd}$ menyebabkan penurunan kemampuan perkecambahan pada tanaman gandum. Lebih lanjut kadungan logam berat $\mathrm{Cd}$ juga mampu menurunkan pertumbuhan pucuk dan akar tanaman bawang putih (Jiang, Liu, \& Hou, 2001) dan menghambat pertumbuhan akar pada tanaman jagung (Wang, Zou, Duan, Jiang, \& Liu, 2007). 
Pengaruh Aplikasi Abu Terbang Batubara

dan Pupuk Kandang terhadap Jumlah Akar

Tanaman Kangkung

Hasil penelitian menunjukkan bahwa aplikasi abu terbang batubara nyata terhadap jumlah akar tanaman kangkung. Ringkasan analisis sidik ragam pengaruh aplikasi abu terbang batubara dan pupuk kandang terhadap jumlah akar tanaman kangkung

Tabel 10. Jumlah akar tanaman akibat aplikasi abu terbang batubara

\begin{tabular}{lc}
\hline $\begin{array}{c}\text { Dosis abu terbang } \\
\text { batubara }\end{array}$ & Jumlah akar \\
\hline $\mathrm{A}_{0}\left(0 \mathrm{tha}^{-1}\right)$ & $19,84 \mathrm{~A}$ \\
$\mathrm{~A}_{1}\left(50 \mathrm{t} \mathrm{ha}^{-1}\right)$ & $15,98 \mathrm{~B}$ \\
$\mathrm{~A}_{2}\left(100 \mathrm{tha}^{-1}\right)$ & $14,84 \mathrm{BC}$ \\
$\mathrm{A}_{3}\left(150 \mathrm{tha}^{-1}\right)$ & $11,20 \mathrm{C}$ \\
\hline BNT $5 \%$ & 3,79 \\
\hline
\end{tabular}

Ket: Angka yang diikuti huruf yang sama pada kolom yang sama tidak berbeda nyata dengan uji BNT pada taraf 5\%.

Tabel 11. Ringkasan analisis sidik ragam bobot kering akar tanaman kangkung akibat aplikasi abu terbang batubara dan pupuk kandang

\begin{tabular}{lc}
\hline \multicolumn{1}{c}{ Sumber Keragaman } & Bobot kering akar $(\mathrm{g})$ \\
\hline Abu terbang batubara $(\mathrm{A})$ & $5,31^{*}$ \\
Pupuk kandang $(\mathrm{K})$ & $0,48^{\text {th }}$ \\
Interaksi AxK & $0,53^{\text {tn }}$ \\
\hline Ket: $^{*}=$ berpengaruh nyata pada taraf $5 \%$, \\
tn $=$ tidak berpengaruh nyata
\end{tabular}

Tabel 12. Bobot kering akar tanaman akibat aplikasi abu terbang batubara

\begin{tabular}{lc}
\hline $\begin{array}{c}\text { Dosis abu terbang } \\
\text { batubara }\end{array}$ & Bobot kering akar $(\mathrm{g})$ \\
\hline $\mathrm{A}_{0}\left(0 \mathrm{tha}^{-1}\right)$ & $0,79 \mathrm{~A}$ \\
$\mathrm{~A}_{1}\left(50 \mathrm{t} \mathrm{ha}^{-1}\right)$ & $0,65 \mathrm{AB}$ \\
$\mathrm{A}_{2}\left(100 \mathrm{tha}^{-1}\right)$ & $0,53 \mathrm{BC}$ \\
$\mathrm{A}_{3}\left(150 \mathrm{tha}^{-1}\right)$ & $0,41 \mathrm{C}$ \\
\hline BNT $5 \%$ & 0,21 \\
\hline
\end{tabular}

Ket: Angka yang diikuti huruf yang sama pada kolom yang sama tidak berbeda nyata dengan uji BNT pada taraf 5\%. disajikan pada Tabel 9. Data menunjukkan bahwa aplikasi pupuk kandang tidak berpengaruh nyata terhadap jumlah akar tanaman kangkung, dan tidak terdapat interaksi antara abu terbang batubara dan pupuk kandang terhadap jumlah akar tanaman. Pengaruh abu terbang batubara terhadap jumlah akar tanaman kangkung disajikan pada Tabel 10. Tabel 10 menunjukkan bahwa peningkatan dosis abu terbang batubara memberikan pengaruh terhadap penurunan jumlah akar tanaman.

\section{Pengaruh Aplikasi Abu Terbang Batubara dan Pupuk Kandang terhadap Bobot Kering Akar Tanaman Kangkung}

Hasil penelitian menunjukkan bahwa aplikasi abu terbang batubara nyata terhadap bobot kering akar tanaman kangkung. Ringkasan analisis sidik ragam pengaruh aplikasi abu terbang batubara dan pupuk kandang terhadap bobot kering akar tanaman kangkung disajikan pada Tabel 11. Hasil menunjukkan bahwa aplikasi pupuk kandang tidak berpengaruh nyata terhadap bobot kering akar tanaman kangkung, dan tidak terdapat interaksi antara abu terbang batubara dan pupuk kandang terhadap bobot kering akar tanaman. Pengaruh abu terbang batubara terhadap bobot kering akar tanaman kangkung disajikan pada Tabel 12. Tabel 12 menunjukkan bahwa dengan peningkatan pemberian dosis abu terbang batubara memberikan pengaruh terhadap penurunan bobot kering akar tanaman, tetapi tidak berbeda dengan pemberian dosis yang lain. 


\section{KESIMPULAN}

Berdasarkan hasil penelitian, maka dapat disimpulkan bahwa (1) peningkatan dosis aplikasi abu terbang batubara menyebabkan penururunan terhadap tinggi tanaman, jumlah daun, bobot kering berangkasan, panjang akar, jumlah akar, dan bobot kering berangkasan tanaman kangkung, (2) aplikasi pupuk kandang tidak meningkatkan pertumbuhan tanaman kangkung, (3) tidak terdapat interaksi antara abu terbang batubara dan pupuk kandang terhadap pertumbuhan tanaman kangkung.

\section{UCAPAN TERIMA KASIH}

Terimakasih diucapkan kepada Kementerian Riset dan Teknologi/Badan Riset dan Innovasi Nasional (RISTEKBRIN) yang telah mendanai penelitian ini melalui skema Penelitian bagi Dosen Pemula.

\section{DAFTAR PUSTAKA}

Ahmad, I., Jamil, A., \& Zahir, Z. A. (2012). Effect of cadmium on seed germination and seedling growth of four wheat (Triticum aestivum L.) cultivars. Pakistan Journal of Botany, 44(5), 1569-1574.

Aiyen. (2004). Importance of Root Growth Parameters to $\mathrm{Cd}$ and $\mathrm{Zn}$ Acquisition by Nonhyperaccumulator and Hyperaccumulator Plants. In Grauer. Germany: Grauer.

Brown, S., Chaney, R., \& Hallfrisch, J. (2004). In Situ Soil Treatments to Reduce the Phyto- and Bioavailability of Lead, Zinc, and Cadmium. Journal of Environmental Quality, 33 (2), 522-531.
Epelde, L., Jauregi, L., Urra, J., Ibarretxe, L., Romo, J., Goikoetxea, I., \& Garbisu, C. (2018). Characterization of Composted Organic Amendments for Agricultural Use. Front. Sustainable Food Syst., 2(44), 1-12.

Jarosz-Krzemińska, E., \& Poluszyńska, P. (2020). Repurposing Fly Ash Derived from Biomass Combustion in Fluidized Bed Boilers in Large Energy Power Plants as a Mineral Soil Amendment. Energies, 13(18), 4805.

Jiang, W., Liu, D., \& Hou, W. (2001). Hyperaccumulation of cadmium by roots, bulbs and shoots of garlic (Allium sativum L.). Bioresource Technology, 76(1), 9-13.

Kishor, P., A.K, G., \& Kumar, D. (2010). Use of Flyash inAgriculture/: A Way to Improve Soil Fertility and its Productivity. Asian Journal of Agricultural Research, 4(1), 1-14.

Leszczynska, D., \& Malina, J. K. (2011). Why you can bank on Candidate Search - now and in. Ecological Chemistry and Engineering, 18(5), 501-507.

Priyadi, Mangiring, W., \& Jamaludin. (2018). Aplikasi Kompos dan Arang Aktif Sebagai Bahan Amelioran di Tanah Berpasir Terhadap Pertumbuhan Tanaman Caisim ( Brassica juncea L.). J. Penelitian Pertanian Terapan, 18(2), 81-86.

PSDMBP. (2019). Neraca Sumber Daya dan Cadangan Batubara Indonesia 2019. Kementerian ESDM.

Ram, L. C., \& Masto, R. E. (2010). An appraisal of the potential use of fly ash for reclaiming coal mine spoil. J. Environ. Manage., 91(3), 603-617. 
Ram, L. C., \& Masto, R. E. (2014). Fly ash for soil amelioration: A review on the influence of ash blending with inorganic and organic amendments. Earth Sci. Rev., 128, 52-74.

Sari, V. I., Sudradjat, \& Sugiyanta. (2015). Peran Pupuk Organik dalam Meningkatkan Efektivitas Pupuk NPK pada Bibit Kelapa Sawit di Pembibitan Utama. Jurnal Agronomi Indonesia (Indonesian Journal of Agronomy), 43(2), 153.

Skousen, J., Ziemkiewicz, P., \& Yang, J. E. (2012). Use of coal combustion by-products in mine reclamation:Review of case studies in the usa. Geosystem Engineering, 15(1), 71-83.

Sondari, N., \& Nurkhalidah, E. S. (2012). Application of Bokashi Botom Ash for Increasing Upland Rice Yield and Decreasing Grain Pb Content in Vitric Hapludans. Journal of Tropical Soils, 17(2), 157.
Tan, K. H. (1991). Dasar-Dasar Kimia Tanah (H. Geonadi \& B. Radjagukguk, eds.). Yogyakarta: Gadjah Mada University Press.

Wang, M., Zou, J., Duan, X., Jiang, W., \& Liu, D. (2007). Cadmium accumulation and its effects on metal uptake in maize (Zea mays L.). Bioresour. Technol., 98(1), 82-88.

Wardani, S. P. R. (2008). Pemanfaatan Limbah Batu Bara ( Fly Ash) Untuk Stabilitas Tanah Maupun Keperluan Teknik Sipil Lainnya Dalam Manggurangi Pencemaran Lingkungan. Universitas Diponegoro.

Widowati, H. (2012). Pengaaruh Logam Berat Cd, $\mathrm{Pb}$ Terhadap Perubahan Warna Batang dan Sayuran. El-Hayah, 1(4), 167-173.

Yourtchi, M. S., \& Bayat, H. R. (2013). Effect of cadmium toxicity on growth, cadmium accumulation and macronutrient content of durum wheat (Dena CV.). IJACS, 6(15), 1099-1103. 